\title{
Long-term consequences of the hidden curriculum on social preferences
}

\author{
Takahiro Ito $^{1} \cdot$ Kohei Kubota ${ }^{2} \cdot$ Fumio Ohtake ${ }^{3}$
}

Received: 19 June 2018 / Revised: 2 September 2019 / Accepted: 6 November 2019 /

Published online: 24 January 2020

(c) The Author(s) 2020

\begin{abstract}
This paper examines the long-term consequences of elementary school curricula on the formation of social preferences. The estimation results, using Japanese data, show that the hidden (non-academic) curriculum at public elementary schools varies widely by region and is associated with preference formation. Specifically, people who have experienced participatory and cooperative learning practices are more likely to be altruistic, cooperative with others, reciprocal, and have national pride. In contrast, education emphasizing anti-competitive practices is negatively associated with these attributes. Such contrasts can also be seen in other preferences regarding government policies and the market economy. The findings imply that elementary school education, as a place for early socialization, plays an important role in the formation of life-long social preferences.
\end{abstract}

Keywords Hidden curriculum · Preference formation - Cultural transmission . Socialization · Elementary education · Japan

JEL codes D90 $\cdot \mathrm{I} 21$

Electronic supplementary material The online version of this article (https://doi.org/10.1007/s4297 3-019-00033-8) contains supplementary material, which is available to authorized users.

Takahiro Ito

takahiro.ito@lion.kobe-u.ac.jp

1 Graduate School of International Cooperation Studies, Kobe University, 2-1, Rokkodai-cho, Nada-ku, Kobe 657-8501, Japan

2 Faculty of Commerce, Chuo University, 742-1 Higashinakano, Hachioji-shi, Tokyo 192-0393, Japan

3 Graduate School of Economics, Osaka University, 1-7 Machikaneyama, Toyonaka, Osaka 560-0043, Japan 


\section{Introduction}

School education is receiving increased attention as a place of socialization. In school, people learn not just cognitive skills, but non-cognitive ones as well, through the formation of preferences, beliefs, and norms. Such preferences and beliefs transmitted subconsciously or unintentionally to students are collectively referred to as the "hidden curriculum," in contrast to the official (academic) curriculum that aims to develop students' cognitive skills-literacy and numeracy (Giroux and Purpel 1983; Kelly 2009).

In the literature, as reviewed in the next section, several studies have focused on the qualitative aspect of education, and demonstrated that specific educational content/practices have an influence on the formation of preferences and beliefs. This paper also aims to explore the link between the school curriculum and the formation of preferences using Japanese data. However, we add to the literature by focusing on the long-term consequences of educational content/practices during elementary education. Most existing studies have primarily investigated the contemporaneous effect of an educational content/practice using the sample of students. But no study has addressed whether the effect of a specific content/practice may be long-lasting, enduring even after the adolescence period ends. Whether, and to what extent, the impact on preference formation persists is especially significant with regard to discussions about policy effectiveness, and for understanding the mechanism of cultural transmission. We shed light on the beliefs and preferences people hold years or decades after their education is complete, using a sample of people between 20 and 60 years old.

This study further contributes to the literature in two ways. First, the outcomes presented here cover a broad range of preferences, from economics and politics to social capital components such as beliefs in trust, cooperation, and reciprocity. In addition, the hidden (non-academic) curriculum we explore includes a variety of educational content/practices: we examine educational content related to politics, economy, ethics, character and peace as well as learning practices such as participatory and non-competitive learning. It is likely that the subject matter in a curriculum is designed to be complementary to and implemented simultaneously with other educational content. If this is the case, focusing exclusively on specific educational content with non-experimental data may confound the influence of other similar content. To our knowledge, this study is the first to comprehensively examine the long-term influences of multiple educational content/practices on the formation of several social and economic preferences.

Second, we focus on educational content/practices during elementary education. Recently, non-cognitive skills have gained recognition in empirical human capital theory, and some researchers emphasize the importance of childhood in the formation of such skills. ${ }^{1}$ Thus, accumulating empirical findings on elementary education,

\footnotetext{
${ }^{1}$ For instance, James $\mathrm{J}$. Heckman, among others, is a leading advocate for this view (Heckman and Krueger 2003).
} 
which could play a decisive role as an early stage of socialization, is important in its own right.

At the same time, however, it would be remiss not to discuss the weaknesses of this study. As will be discussed in Sect. 3.3, our identification strategy relies on the assumption that variations in the hidden curriculum in Japanese elementary schools are exogenous to pupils (at least before the 2000s). Thus, a strong claim about causality cannot be made in the absence of an experimental setting, such as the random assignment of school placement or policy implementation. However, various checks show that our identification strategy is relatively plausible in the context of elementary education before the 2000s in Japan. We believe that our approach-exploring the prolonged effects of the hidden curriculum based on the assumption-is one of the most reliable approaches available with observational data.

The rest of the paper is organized as follows. In Sect. 2 we review the literature on the impact of school education on preference formation and describe educational content/practices in Japan. Section 3 presents the empirical framework, i.e., the data and empirical specification used in the analysis. Section 4 reports the estimation results, and Sect. 5 discusses the validity of our identification assumption. The estimation results show that people who experienced participatory and cooperative learning practices during their elementary education are more likely to be altruistic, cooperative with others, reciprocal, and have national pride after they grew up. In contrast, education emphasizing anti-competitive practices is negatively associated with these attributes. Such contrasts can also be seen in other preferences regarding government policies and the market economy. The findings imply that elementary school education, as a place for early socialization, plays an important role in the formation of life-long social preferences. Various checks show that the findings are robust after eliminating possible confounding factors or potential reverse causality. Finally, Sect. 6 concludes the paper.

\section{Background}

\subsection{Education and socialization: a literature review}

An increasing number of researchers are interested in how people's preferences and beliefs are formed within a society. The formation of preferences and beliefs has been documented in the field of cultural transmission and socialization. ${ }^{2}$ The socialization mechanisms of preferences, beliefs, and norms can be broadly classified into two channels: direct vertical socialization (through family), and horizontal and oblique socialization (through, for example, friends, neighbors, teachers, or mass media). Among the latter mechanisms, school education is considered one of the more important channels of socialization.

In the literature on the role of school education in preference formation, there are two broad strands of study: one involving those who have focused on the qualitative

\footnotetext{
${ }^{2}$ See Bisin and Verdier (2011) for an extensive review of the literature in this field.
} 
aspects of education, and the other on the quantitative aspects of education. The study of the qualitative aspects of education has addressed specific educational content and practices and their role in preference formation. For example, Algan et al. (2013) examined the relationship between teaching practices and students' beliefs using samples of primary and lower-secondary school students from international datasets. Utilizing within-school variations in educational practices, they found a positive impact of "working-in-groups" practices on students' beliefs about cooperation and trust. Focusing on China's curriculum reform in the 2000s, Cantoni et al. (2017) explored the influence of the politics curriculum at upper-secondary schools on political beliefs using a sample of university students. They exploited cohortregional variations in the timing of the introduction of new textbooks and documented that changes in the politics curriculum altered students' views on China's governance, democracy and free markets.

In addition, Alan and Ertac (2017) conducted a randomized educational intervention in Turkey to investigate the influence of an educational program aiming to cultivate optimistic views about the role of effort in success. They provided evidence for the causal relationship between beliefs about effort and altruistic behavior, using a sample of elementary students. Treated children who received the program were less likely to donate when the recipient was poor (in terms of experimental earnings) due to his/her own failure, while there were no differences in donation behavior between the treated and control children when the recipient was poor due to chance.

In the second strand of literature, researchers have focused on the quantity of education (often measured by years of education), but not specific education curricula. For instance, Milligan et al. (2004) found that increases in education due to changes in compulsory school laws have a positive impact on voter turnout in the United States. Helliwell and Putnam (2007) also show schooling years are positively associated with trust and civic participation in the United States. On the other hand, Friedman et al. (2016), who used a randomized girls' scholarship programme in Kenya, found that the programme increases girls' educational attainment, but does not increase civic participation. ${ }^{3}$

The impact of a quantitative increase in education, on preference formation, may differ according to the specific stage of education. For instance, Heckman and Raut (2016) found that preschool experience is positively associated with a self-reported socialization skill (at the age of 6) using a sample of children and young adults aged between 14 and 22 in the United States. Cappelen et al. (2017) also found a causal relationship between preschool education and preference formation. They utilized a randomized education project for preschool-age children (and their parents) in the United States and found that treated students who received a free 9-month full-day preschool were more likely to be egalitarian compared to those who did not.

Clots-Figueras and Masella (2013) presented a study which can be viewed as focusing on both the qualitative and quantitative aspects of education. They

\footnotetext{
3 In addition, using a national representative survey in the United States, Hryshko et al. (2011) found indirect evidence of the role of the quantity of education: Parents' schooling years lower the risk aversion of their children.
} 
exploited reforms in language policies in an autonomous community in Spain in 1983, and investigated the impact of the length of education in the local language at school, on national identity formation. They found that people who had been exposed to local language instruction at school for a longer period were more likely to have an ethnic consciousness and vote for an ethnic party.

The present study also focuses on specific educational content and practices, as the first strand of studies did, but differs from them in certain ways. First, this study addresses whether the effects of educational content/practices persist after completing one's education, entered the labor market, or gained a wider variety of life experiences. The long-term impacts of education have been documented primarily in the literature on education quantity, but little is known about specific school curricula. ${ }^{4}$ Studies on the quantity of education often cannot identify a specific channel through which the length of education might have an influence on preference formation. We employ a wide variety of educational content/practices and social preferences, and aim to derive more specific implications of educational policies based on a longterm perspective.

\subsection{Educational content and practices in Japan}

The content and practices of school education in Japan are basically stipulated in the school curriculum. From the elementary level, through high school, the curriculum is based on the School Curriculum Guidelines (Gakushu Sidou Youryou) of the Ministry of Education, Culture, Sports, Science and Technology (MEXT). ${ }^{5}$ However, while all public schools seem to provide uniform education based on the same guidelines, actual educational content/practices, in particular, non-academic ones that are not written in the guidelines, are not necessarily identical.

For instance, elementary schools, almost without exception, hold an annual school sports meet in which pupils are separated into two teams and compete in several athletic events, even though this is not specifically mentioned in the guidelines. Therefore, regional or generational differences exist in the actual content of events. Usually, in a sports meet, pupils compete in a 50-m footrace with five or six peers, and points are added to the teams of the pupils who win the first and second prizes. However, in some schools, there are no footraces. Or if there are, teachers do not rank pupils' finishing order. Another example is peace and anti-discrimination education. Almost all elementary schools in Japan offer a school trip for sixth-grade pupils, consisting of multiday tours, to broaden their knowledge. In western Japan, the destination for these tours tends to be Hiroshima or Nagasaki (cities on which the atomic bombs were dropped) to learn about the misery of war and importance of peace. Similarly, schools in western Japan tend to provide anti-discrimination

\footnotetext{
${ }^{4}$ Based on a similar empirical strategy, our companion paper, Kubota et al. (2019), investigated the long-term consequences of the experience of group work at elementary school focusing on labor market outcomes, the formation of social preferences and subjective well-being using different Japanese data.

5 Private schools, as well as public schools, are required to follow the guidelines. However, they are more strictly applied to public schools.
} 
education (dowa kyoiku) and hold school assemblies in remembrance of the nuclear blasts (August 6 or 8). However, no such tendencies are observed in other regions.

In addition to these practices, this paper focuses on several regions- or generation-specific content/practices, as explained later. Note, however, that this does not mean that nationwide practices are of no importance. For instance, the "Stand up. Bow. Sit down." greeting offered both before and after class, the daily school cleaning by pupils, ${ }^{6}$ the school sports meets, and school trips are well-known nationwide content/practices in Japan. Although it is expected that these practices influence pupils' socialization, it is impossible to isolate the effects of a variable that exhibits little variation. While cross-country analysis focusing on such nation-specific educational content/practices may provide valuable insights, enabling us to investigate differences in national character or culture, such a task is beyond the scope of this study.

\section{Empirical framework}

\subsection{Survey and data}

To investigate people's educational experiences and determine their preferences and beliefs, we carried out an original survey in October 2012. The survey was conducted online through a Japanese market research company under the authors' directions. ${ }^{7}$ Based on the size of our research budget, we set the target number of respondents at 4,500. Then, considering average response rates, the survey company sent invitation e-mails to 14,628 potential participants. To ensure sufficient variation among respondents' past educational experiences, we employed quotasampling based on age, gender, and region (five age categories, two genders, and nine regions), ${ }^{8}$ and we obtained 4,709 survey responses. In the analysis, we use a sampling weight so that our sample's age-gender-region distribution is proportional to the actual age-gender-region distribution in Japan. The actual distribution of the Japanese population is calculated from the 2010 Population Census of Japan.

Table 1 reports sample features such as marital status and education level. The table also presents the same information calculated from national representative data for comparison

\footnotetext{
${ }^{6}$ Greetings before/after class are a sequence of actions that pupils perform, such as standing up, bowing, and sitting down to show their respect for teachers. Daily school cleaning by pupils is also a common practice in Japanese schools. Usually, pupils clean their classroom, school playground, or gymnasium for about 20 min before afternoon classes every day.

7 The survey company is MyVoice Communications Inc. It started conducting Internet surveys in 1998 and had more than one million registered survey panelists as of November 2013. It has a rigorous data quality control system to obtain highly reliable data. For instance, all registrants are checked strictly by examining their registration information, and about one-fourth of new registrants are eliminated beforehand due to inconsistent characteristics or double registration. In addition, the survey panelists are regularly monitored, and the number of surveys in which one panelist can participate is controlled (average frequency in 1 year is about 13).

${ }^{8}$ The nine regions comprise Hokkaido, Tohoku, Kanto, Hokuriku, Chubu, Kinki, Chugoku, Shikoku, and Kyushu.
} 
Table 1 Sample characteristics. Source: Authors' survey and Labor Force Survey (2012)

\begin{tabular}{lll}
\hline & Unmarried (\%) & $\begin{array}{l}\text { Graduates/post } \\
\text { graduates (\%) }\end{array}$ \\
\hline $\begin{array}{ll}\text { A. Our survey (2012) } \\
\text { Total (age } 20 \text { or older) }\end{array}$ & 37.2 & 47.5 \\
Ages 20 to 24 & 94.5 & 39.8 \\
Ages 25 to 34 & 68.6 & 55.3 \\
Ages 35 to 44 & 37.4 & 45.5 \\
Ages 45 to 54 & 20.1 & 45.6 \\
Ages 55 to 64 & 9.3 & 45.9 \\
Age 65 or older & 4.0 & 37.7 \\
B. Labor Force Survey (2012) & & \\
Total (age 15 or older) & 25.8 & 20.9 \\
Ages 15 to 24 & 96.5 & 21.8 \\
Ages 25 to 34 & 52.0 & 34.4 \\
Ages 35 to 44 & 22.8 & 26.7 \\
Ages 45 to 54 & 13.7 & 25.8 \\
Ages 55 to 64 & 7.9 & 19.3 \\
Age 65 or older & 3.3 & 9.0 \\
\hline
\end{tabular}

(Panel B). As can be seen from the table, respondents in our survey are more likely to have a college degree (or higher) than Labor Force Survey respondents. This is because our survey was conducted online, and highly educated people have a tendency to use the Web more frequently. In particular, elderly cohorts seem to be more skewed toward the highly educated.

In our empirical analysis, out of the 4,709 respondents, 894 individuals aged 60 and older were excluded. This is partly due to the sample bias concern mentioned above, but mainly due to their educational background: individuals aged 60 and older received their elementary education in wartime or postwar turmoil. The education system changed significantly during the occupation period by the Allied Powers (1945-1952). In addition, 125 respondents who graduated from a private elementary school (3.3\% of the sample) and 69 respondents with missing information for some characteristics $(1.8 \%)$ were also excluded from the analysis. Thus, the sample used in the analysis consists of 3,621 respondents.

Regarding their school education, respondents were asked whether they had experienced any of the 17 educational practices or types of content shown in Table 2. These 17 variables have been employed for several generations in some regions, but not in others. Such regional and generational disparities are presumed to reflect differences in the hidden curriculum. Empirical issues regarding subjective and retrospective data (experience with educational content/practices) will be discussed in Sect. 5.3. ${ }^{9}$

\footnotetext{
9 Note also that the 17 content/practices in the table were selected based on the authors' discussions and preliminary interviews with several people, including colleagues. We admit that there are other region- and generation-varying non-academic curricula than these, and omitting them may be problematic in estimating the impact of school curricula. However, the same goes for previous studies focusing only on a single educational content/practice if the omitted factors are confounded with it. Including all possible curricula is not feasible, and no study has examined educational content/practices more comprehensively than ours.
} 


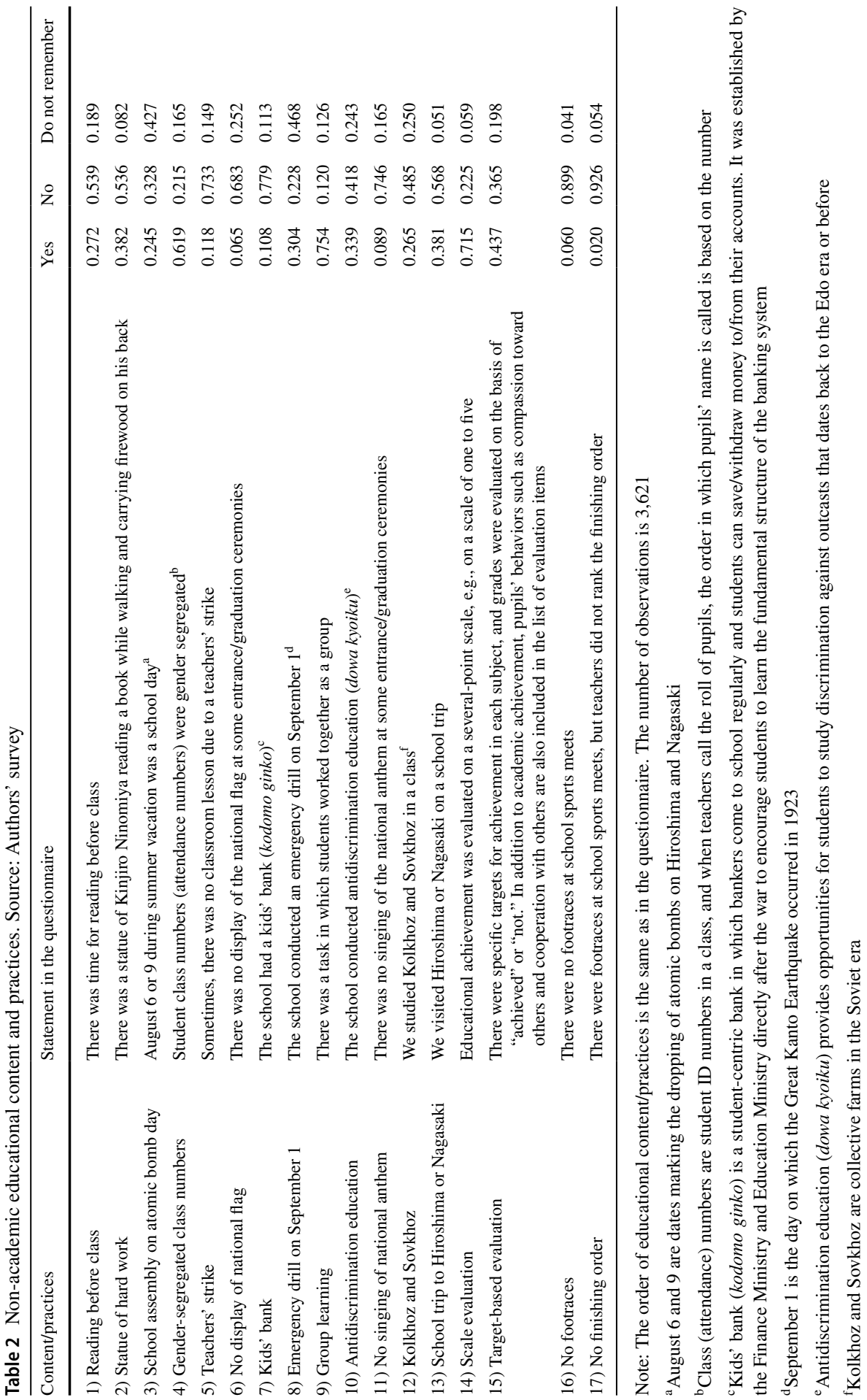




\subsection{Empirical specification}

We estimate the impact of the hidden (non-academic) curriculum of elementary school education $\left(\boldsymbol{H}_{i}\right)$ on the formation of social or economic preferences $\left(\right.$ Pref $\left._{i}\right)$ based on the following equation:

$$
\operatorname{Pref}_{i}=\alpha+\boldsymbol{H}_{i} \boldsymbol{\beta}+\boldsymbol{X}_{i} \boldsymbol{\gamma}+\varepsilon_{i},
$$

where $i$ indexes individuals, $\boldsymbol{X}_{i}$ is a vector of controls (individual, household, and community/school characteristics), $\varepsilon_{i}$ is an unobserved component affecting preference formation, and $\alpha, \boldsymbol{\beta}$, and $\boldsymbol{\gamma}$ are the parameters to be estimated.

The outcomes of interest are social and economic preferences $\left(\right.$ Pref $\left._{i}\right)$ such as altruism, beliefs in cooperation and trust, reciprocity, and attitudes toward government redistributive policies and market institutions. Based on respondents' answers to the standard questions, we measure these preferences/beliefs (see Table 3), by constructing binary variables which take unity if the respondent agrees ("agree" and "strongly agree") with the corresponding question, and zero otherwise ("strongly disagree," "disagree," and "neither agree nor disagree"). Thus, in the analysis we estimate a linear probability model based on Eq. (1). ${ }^{10}$

Regarding the hidden curriculum $\left(\boldsymbol{H}_{i}\right)$, we employ factor analysis to extract factors comprising the hidden curriculum that lie behind actual educational content/ practices. The result is shown in Table 4. The reported figures are rotated factor loadings, obtained by polychoric factor analysis using the principle component factor (PCF) method, with an oblique promax rotation. Considering the Kaiser criterion and the Scree test, five factors are retained. The sensitivity of analysis for the measurement of the hidden curriculum is provided in Sect. 5.3.

The first factor has large loadings for "no display of the national flag" and "no singing of the national anthem." These practices are thought to be based on reflections of the last World War and associated with leftist political viewpoints, such as anti-war and anti-nationalist ideologies. "Teachers' strike" is also associated with leftist thinking. Thus, the first factor is referred to as "leftist political thought." The second factor is strongly related to "no footraces" and "no finishing order." These practices aim to turn pupils away from competition, and therefore we call this factor "anti-competition." The third factor consists mainly of "group learning," "reading before class," "emergency drill on September 1," and "target-based evaluation." We refer to this factor as "participation \& cooperation," because most of these practices require pupils' active participation and/or cooperation amongst each other. Note that "target-based evaluation" often includes, in the list of evaluation items, behaviors such as compassion toward and cooperation with others as well as academic achievement. The fourth factor is related to "Kolkhoz and Sovkhoz," "kid's bank," "scale evaluation" and "statue of hard work (a statue of Kinjiro Ninomiya reading a book while walking and carrying firewood on his back)." Because these educational

\footnotetext{
${ }^{10}$ An alternative approach may be to use the maximum likelihood method. For example, run the probit and the ordinary probit models using the binary and five-scale responses. However, we avoid assuming a specific error distribution and employ the ordinary least square (OLS) estimation. We discuss the sensitivity to the choice of the outcome variables and methods in Sect. 5.4.
} 


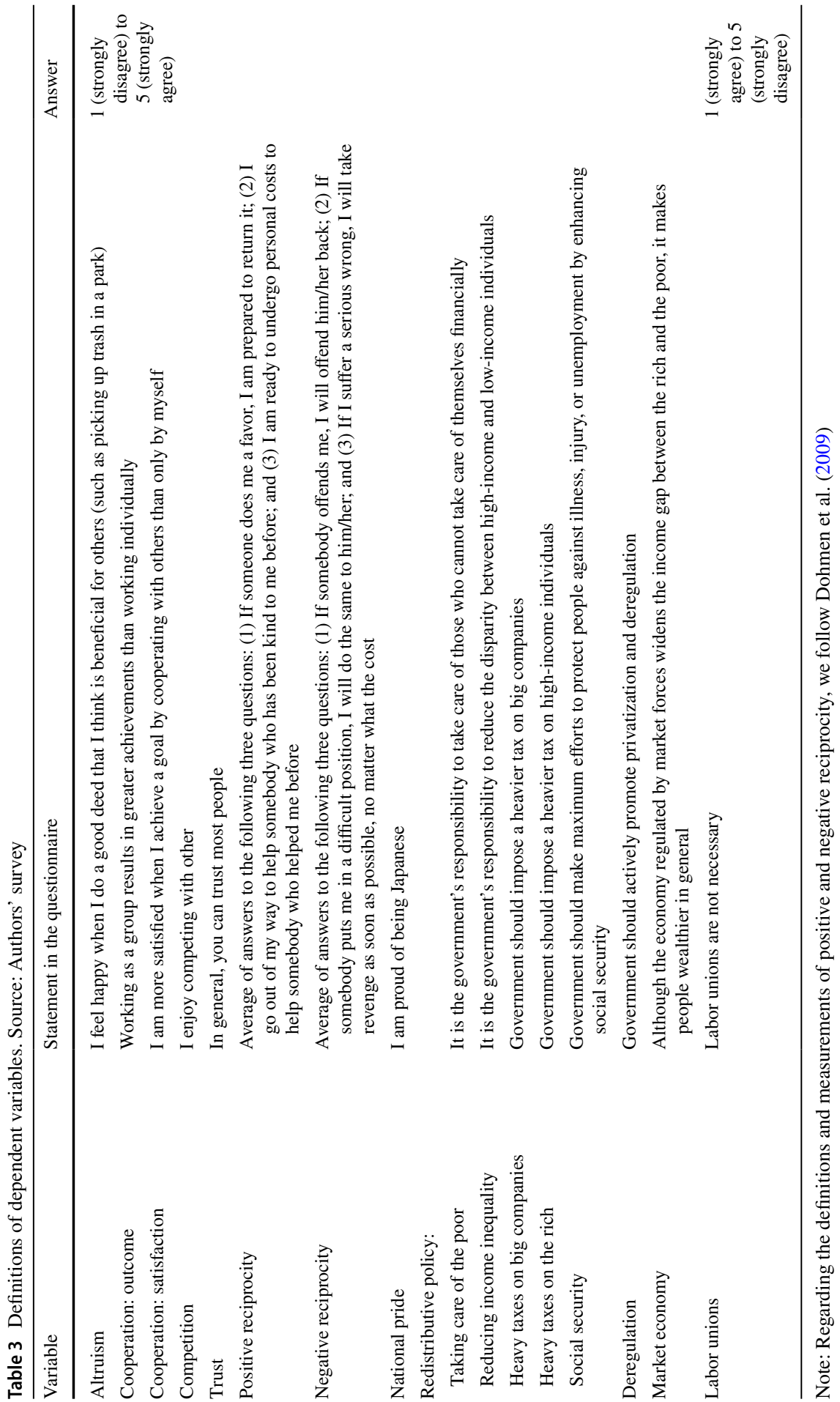




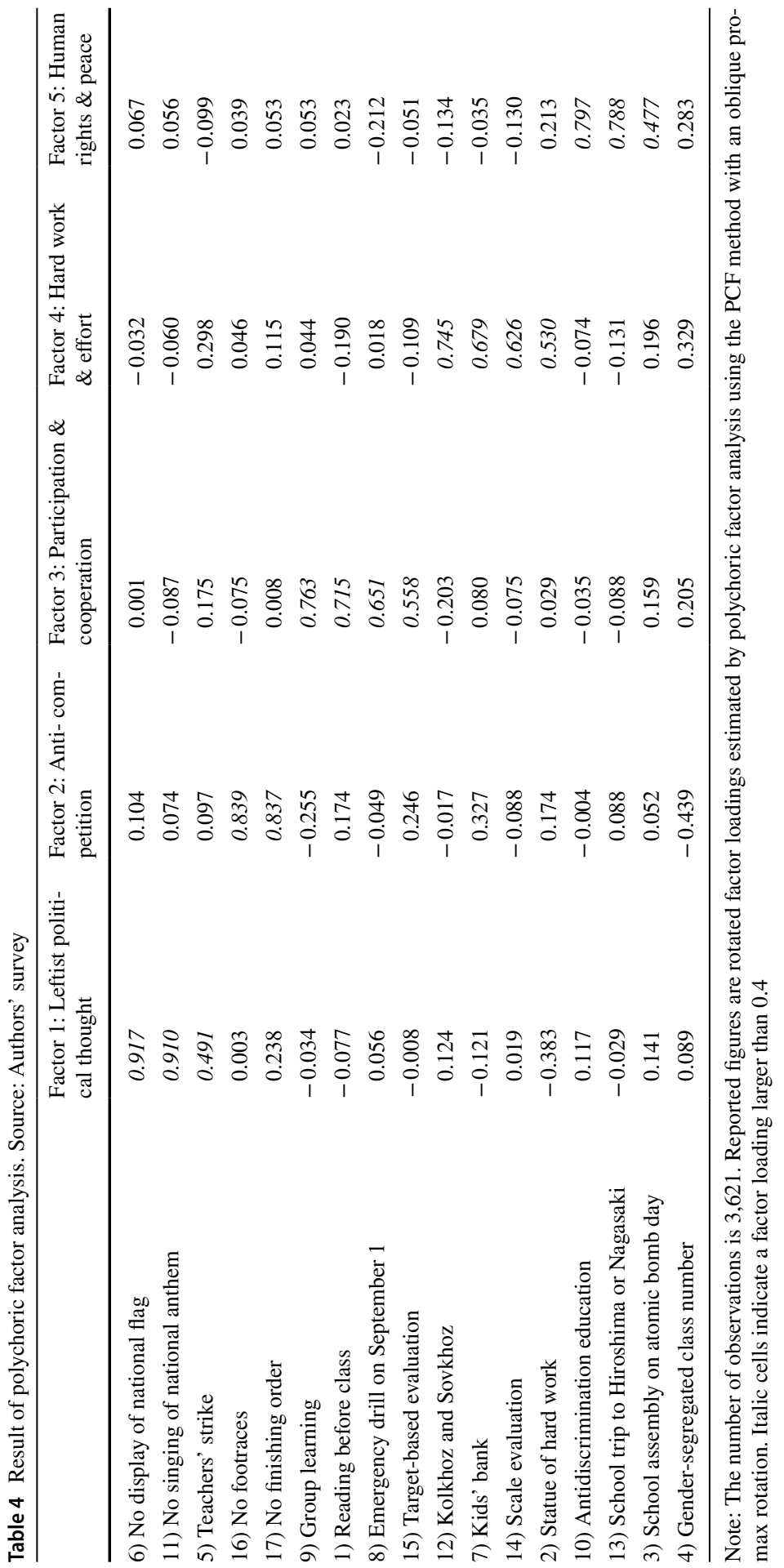


practices aim to teach the importance of industriousness, we call this factor "hard work \& effort." The final factor is strongly related to "anti-discrimination education," "school trip to Hiroshima or Nagasaki," and "school assembly on atomic bomb day," and is referred to as "human rights \& peace." "Gender-segregated class number" has small factor loadings for all five factors. Segregation by gender is associated with traditional Japanese thought, and this might be the reason this practice has a relatively large positive loading for Factor 4 ("hard work \& effort") and negative loading for Factor 2 ("anti-competition") because industriousness is also related to traditional values in Japan.

Figure 1 maps average scores of the five factors by prefecture. As seen in the figure, our proxies for the hidden curriculum vary widely between prefectures. While "leftist political thought" (Panel A), "anti-competition" (Panel B), and "hard work \& effort" (Panel D) appear dispersed nationwide, both "participation \& cooperation" (Panel C) and "human rights \& peace" (Panel E) have a regional tendency. In this case, the former is practiced more in central Japan and the latter in western Japan. Note, however, that the hidden curriculum is not uniform within a prefecture. The two-level nested analysis of variance (ANOVA) in Table A1 in Online Appendix I shows that while the between-prefecture (at the age of 12) variation is much larger than the between-municipality (city/ward/county at the age of 12) variation for all five factors, between-municipality variation is also larger than within-municipality variation. This indicates that the hidden curriculum differs largely between prefectures, but also between schools within the same prefecture.

Besides geographical disparities, we observe generational differences for some factors (Table 5). For instance, Factor 4 ("hard work \& effort") varies from generation to generation: older generations are more likely to receive education emphasizing "hard work \& effort." In contrast, the average factor scores for Factor 3 ("participation \& cooperation") are higher among younger generations. This implies that there has been a nationwide shift of educational content/practices from "hard work \& effort" to "participation \& cooperation." As implied by Fig. 1 and Table 5, the key source of variation for identifying the effect of the hidden curriculum appears to stem from the regional and generational differences in actual educational content/ practices.

Regarding other controls $\left(X_{i}\right)$ in Eq. (1), guided by empirical literature, we employ individual characteristics (5-year birth cohort dummies, education dummies, female dummies, interactions between the 5-year birth cohort and education dummies, marital status dummies, income category dummies, and household size), family background (parents' education dummies, number of books at home, dummies for living with grandparents at age 15, and number of siblings at age 15), school (or school district) characteristics (class size, dummy for experience of classroom chaos, dummy for teachers' active intervention with bullying, and number of high schools that can be chosen in a school district), ${ }^{11}$ and prefecture dummies (current and at the age of 12). Note that differences in regional and generational tendencies found in Fig. 1 and Table 4 are controlled by prefecture and birth cohort fixed effects.

\footnotetext{
${ }^{11}$ Note that school (district) variables are retrospective data directly surveyed from respondents in the same survey.
} 


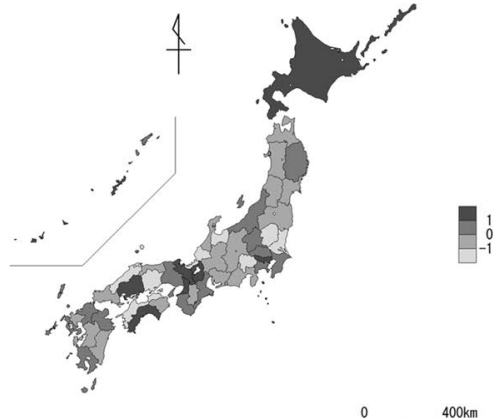

(a)

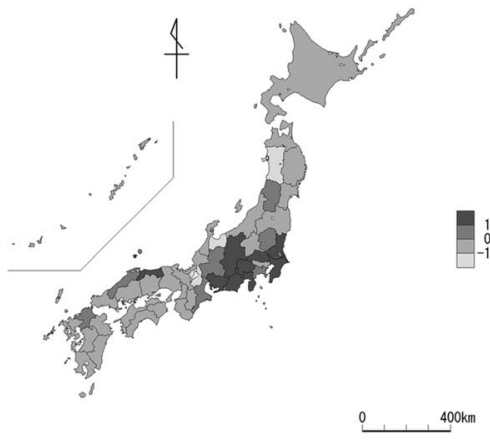

(c)



(e)

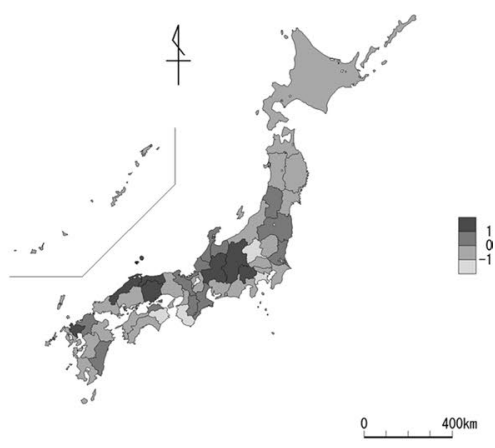

(b)

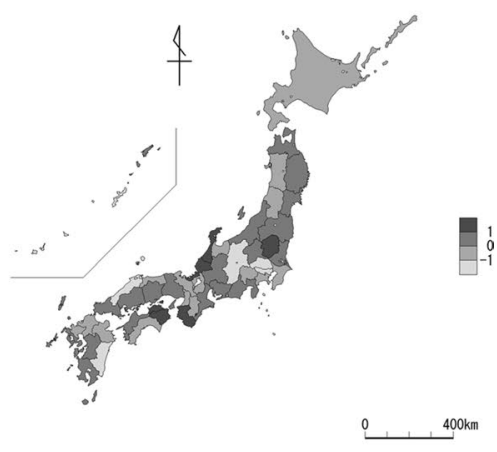

(d)

Fig. 1 Factor Scores by Prefecture. a Leftist political thought. b Anti-competition. c Participation \& cooperation. d Hard work \& effort. e Human rights \& peace (source: Authors' survey) 
Table 5 Factor Scores by Age Group. Source: Authors' survey

\begin{tabular}{lcccc}
\hline Age group & $20-29(N=918)$ & $30-39(N=924)$ & $40-49(N=908)$ & $50-59(N=871)$ \\
\hline F1: Leftist political thought & 0.195 & 0.394 & 0.403 & 0.394 \\
F2: Anti-competition & -0.253 & -0.750 & -0.857 & -0.785 \\
F3: Participation \& coopera- & 2.186 & 1.641 & 1.579 & 1.516 \\
$\quad$ tion & 1.123 & 1.515 & 1.865 & 2.229 \\
F4: Hard work \& effort & 1.140 & 1.303 & 1.197 & 1.052 \\
F5: Human rights \& peace & & & & \\
\hline
\end{tabular}

\subsection{The identification assumption}

Our identification strategy hinges on the assumption that the hidden curriculum that pupils experience at public elementary schools is an exogenous variable, outside of the students' control. While one might assume this is unlikely as, in general, people tend to choose their school based on the academic curriculum, for the reasons mentioned below, we believe that this assumption is, in fact, relatively plausible in the context of Japanese elementary education.

First, the school curricula in elementary schools are stipulated by the School Curriculum Guidelines set out by the government, and therefore, educational content/practices, in particular, academic ones, are fundamentally homogeneous across the country. In addition, all textbooks used in elementary schools must be those approved by the Ministry of Education (Textbook Authorization System).

Furthermore, it is not possible to compare schools directly in terms of pupils' academic performance. The result of the national academic achievement test is not publicly disclosed at the school level. Although it is published at the prefecture level, even municipality level data are rarely available. Besides, prior to 2014, municipalities were not allowed to publish the results. As such, for the respondents in our dataset, where the youngest cohort (20 years old in 2012) enrolled in elementary school more than 20 years ago, it was hard to choose their school based on the academic curricula or performance.

The school district system (zoning rule) may also hinder endogenous school choice. Under this system, children may only attend the school in their school district. The school district system has been relaxed in some municipalities since $1997,{ }^{12}$ but only $3.4 \%$ of our sample (people in the youngest cohort who entered elementary school in 1998) were exposed to the reform and only $3 \%$ of the municipalities had adopted a school choice system by 1998. Therefore, we expect the policy reform to have little influence on our analysis.

\footnotetext{
12 In 1997, the Ministry of Education issued a notice that municipal education boards were allowed to relax the school district boundaries and introduce a school choice system in elementary and junior high schools. It is easily imaginable that schools in the municipalities which introduced a school choice program would attempt to differentiate the educational content/practices from the competition to attract more students. Consequently, this could lead students to sort into schools on the basis of educational reputation (see, for example, Yoshida et al. 2009, for the case of junior high schools in a ward of the Tokyo metropolitan area).
} 
"Privatization" of education could be an alternative, but parents generally have limited choice in the "private" sector. In Japan, almost all elementary schools are publicly operated (about 99\%), and a private tutoring or preparatory school is the only other available option. In Sect. 5, we more intensively explore the validity of our identification assumption.

\section{Estimation results}

\subsection{Social preferences}

We start this section by estimating the basic specification in Eq. (1) for social preferences. Empirical variables used in the analysis are summarized in Table 6, and the estimation results are reported in Table 7. All estimations are implemented with ordinary least-squares (OLS) controlling individual characteristics, family background, school (school district) characteristics, and prefecture dummies (current and at age 12), as explained in Sect. 3.2. In addition, we adjust the sampling weight to make our observations proportional to the overall Japanese population distribution.

From the estimation results, we see contrasts between "anti-competition" (row 2) and "participation \& cooperation" (row 3). Those who experienced education that implemented participatory/cooperative learning practices are more likely to favor altruistic behavior (column 1), cooperation with others (columns 2 and 3), and reciprocal behavior (column 6). In contrast, those who experienced education that implemented anti-competitive practices are less likely to favor altruistic behavior (column 1), cooperation with others (column 2), and reciprocal behavior (columns 6 and 7). Interestingly, the sign of the coefficient differs between the case of positive reciprocity (column 6) and negative reciprocity (column 7), suggesting that those who experienced anti-competitive education prefer not to repay a debt but to make a countercharge. In addition, the last column shows that "anti-competition" is negatively associated with national pride, whereas "participation \& cooperation" is positively associated with it.

Turning to the other factors of the hidden curriculum, "hard work \& effort" and "human rights \& peace" have a statistically significant impact on some preferences. For instance, people who received education valuing "hard work \& effort" at elementary school are less cooperative and more revengeful but have high trust in others. On the other hand, education emphasizing "human rights \& peace" are associated with competitive character and national pride.

Regarding the contrasts between "anti-competition" and "participation \& cooperation," one might wonder why they are conversely associated with the formation of social preferences, even though they seemingly share a similar goal, i.e., egalitarian education. As egalitarian education is naturally expected to enhance people's prosocial behavior, anti-competitive education must positively influence beliefs regarding cooperation and reciprocity. For this apparently contradictory result, Kariya's (1995) insight is highly suggestive. He pointed out that in anti-competitive education, differences in pupils' achievements are considered to be attributed to differences in teachers' teaching skills rather than differences 
Table 6 Summary of statistics on empirical variables. Source: Authors' survey

\begin{tabular}{|c|c|c|c|c|c|}
\hline Variable & NOBs & Mean & Std. dev. & Min. & Max. \\
\hline \multicolumn{6}{|l|}{ Social and economic preferences (Dummy) } \\
\hline Altruism & 3,621 & 0.568 & 0.495 & 0 & 1 \\
\hline Cooperation: outcome & 3,621 & 0.431 & 0.495 & 0 & 1 \\
\hline Cooperation: satisfaction & 3,621 & 0.426 & 0.495 & 0 & 1 \\
\hline Trust & 3,621 & 0.247 & 0.431 & 0 & 1 \\
\hline Competition & 3,621 & 0.258 & 0.438 & 0 & 1 \\
\hline Positive reciprocity & 3,621 & 0.826 & 0.379 & 0 & 1 \\
\hline Negative reciprocity & 3,621 & 0.216 & 0.411 & 0 & 1 \\
\hline National pride & 3,621 & 0.595 & 0.491 & 0 & 1 \\
\hline Income redistribution: poor & 3,621 & 0.349 & 0.477 & 0 & 1 \\
\hline Income redistribution: inequality & 3,621 & 0.387 & 0.487 & 0 & 1 \\
\hline Government tax: companies & 3,621 & 0.439 & 0.496 & 0 & 1 \\
\hline Government tax: wealthy individuals & 3,621 & 0.644 & 0.479 & 0 & 1 \\
\hline Social security & 3,621 & 0.641 & 0.480 & 0 & 1 \\
\hline Deregulation & 3,621 & 0.394 & 0.489 & 0 & 1 \\
\hline Market economy & 3,621 & 0.277 & 0.448 & 0 & 1 \\
\hline Labor union & 3,621 & 0.391 & 0.488 & 0 & 1 \\
\hline \multicolumn{6}{|l|}{ Hidden curriculum } \\
\hline F1: Leftist political thought & 3,621 & 0.346 & 1 & -1.195 & 5.010 \\
\hline F2: Anti-competition & 3,621 & -0.659 & 1 & -2.483 & 4.989 \\
\hline F3: Participation \& cooperation & 3,621 & 1.734 & 1 & -0.361 & 4.416 \\
\hline F4: Hard work \& effort & 3,621 & 1.675 & 1 & -0.410 & 4.753 \\
\hline F5: Human rights \& peace & 3,621 & 1.175 & 1 & -0.568 & 3.718 \\
\hline \multicolumn{6}{|l|}{ Other controls } \\
\hline $\operatorname{Age}^{\mathrm{a}}$ & 3,621 & 39.534 & 10.881 & 20 & 59 \\
\hline Schooling years ${ }^{b}$ & 3,621 & 14.37 & 2.123 & 9 & 21 \\
\hline Female dummy & 3,621 & 0.501 & 0.5 & 0 & 1 \\
\hline \multicolumn{6}{|l|}{ Marital status dummies } \\
\hline Divorced & 3,621 & 0.042 & 0.201 & 0 & 1 \\
\hline Bereaved & 3,621 & 0.004 & 0.063 & 0 & 1 \\
\hline Unmarried & 3,621 & 0.371 & 0.483 & 0 & 1 \\
\hline Income (million yen) ${ }^{b}$ & 3,419 & 273.062 & 293.118 & 0 & 1500 \\
\hline Household size $^{\mathrm{b}}$ & 3,389 & 2.867 & 1.15 & 1 & 5 \\
\hline Father's schooling years ${ }^{b}$ & 3,089 & 12.387 & 2.703 & 9 & 21 \\
\hline \multicolumn{6}{|c|}{ Health status dummies (Reference category: Very good) } \\
\hline Good & 3,621 & 0.329 & 0.470 & 0 & 1 \\
\hline Okay & 3,621 & 0.282 & 0.450 & 0 & 1 \\
\hline Bad & 3,621 & 0.133 & 0.340 & 0 & 1 \\
\hline Very bad & 3,621 & 0.024 & 0.154 & 0 & 1 \\
\hline Mother's schooling years ${ }^{b}$ & 3,107 & 11.799 & 2.032 & 9 & 21 \\
\hline \multicolumn{6}{|c|}{ \# of books at home (Dummy; Reference category: More than 100) } \\
\hline 50 to 99 books & 3,621 & 0.122 & 0.327 & 0 & 1 \\
\hline
\end{tabular}


Table 6 (continued)

\begin{tabular}{lccccc}
\hline Variable & NOBs & Mean & Std. dev. & Min. & Max. \\
\hline 10 to 49 books & 3,621 & 0.407 & 0.491 & 0 & 1 \\
1 to 9 books & 3,621 & 0.152 & 0.359 & 0 & 1 \\
No books & 3,621 & 0.019 & 0.137 & 0 & 1 \\
Do not remember & 3,621 & 0.138 & 0.345 & 0 & 1
\end{tabular}

Living together with grandparents at age 15 (Dummy; Reference category: Did not live with grandparents)

$\begin{array}{llllll}\text { Less than a year } & 3,621 & 0.027 & 0.162 & 0 & 1 \\ \text { Less than 5 years } & 3,621 & 0.066 & 0.248 & 0 & 1 \\ \text { Less than 10 years } & 3,621 & 0.058 & 0.234 & 0 & 1 \\ \text { More than 10 years } & 3,621 & 0.284 & 0.451 & 0 & 1 \\ \text { \# of elder siblings } & 3,621 & 0.601 & 0.795 & 0 & 6 \\ \text { \# of younger siblings } & 3,621 & 0.742 & 0.769 & 0 & 7\end{array}$

\# of high schools in the school district (Dummy; Reference category: 1 school)

$\begin{array}{llllll}2 \text { to } 4 \text { schools } & 3,621 & 0.238 & 0.426 & 0 & 1 \\ 5 \text { to 9 schools } & 3,621 & 0.267 & 0.442 & 0 & 1 \\ \text { More than 10 schools } & 3,621 & 0.146 & 0.353 & 0 & 1 \\ \text { Do not remember } & 3,621 & 0.225 & 0.418 & 0 & 1 \\ \text { Class size } & 3,621 & 36.043 & 8.094 & 1 & 80 \\ \text { Classroom chaos (Dummy) } & 3,621 & 0.257 & 0.437 & 0 & 1 \\ \text { Teachers' active intervention (Dummy) } & 3,621 & 0.263 & 0.440 & 0 & 1 \\ \text { Percentage of "do not remember" to the 17 } & 3,621 & 0.174 & 0.167 & 0 & 1 \\ \quad \text { educational questions } & & & & & \end{array}$

Note: "Age" is controlled as 5-year age group dummies

${ }^{\mathrm{b}}$ All variables are controlled as dummy variables. In case of missing values, a dummy for missing values is controlled

in pupils' natural abilities, and this is the reason the rank of pupils' achievements in class or school is not revealed to pupils. Such an educational thought may lead pupils to think that people are equal in terms of natural ability and that performance is a result of their own effort.

In this relation, the negative influences of education emphasizing hard work and effort, on beliefs about cooperation, can also be explained by a sense of selfresponsibility for results. Then, the difference between "hard work \& effort" and "anti-competition" appears in their effects on beliefs about altruism and trust: While "hard work \& effort" seems to be related to a sense of self-responsibility, "anti-competition" seems to be associated with a sense of self-interest. Thus, the results for "hard work \& effort" may be explained in line with Alan and Ertac (2017) findings. As outlined in Sect. 2.1, their results indicate that beliefs on the role of efforts in success disincentivize people's prosocial behavior but do not reduce altruism itself. That is, optimistic views on the role of effort in success may cultivate self-responsibility but not selfishness. 


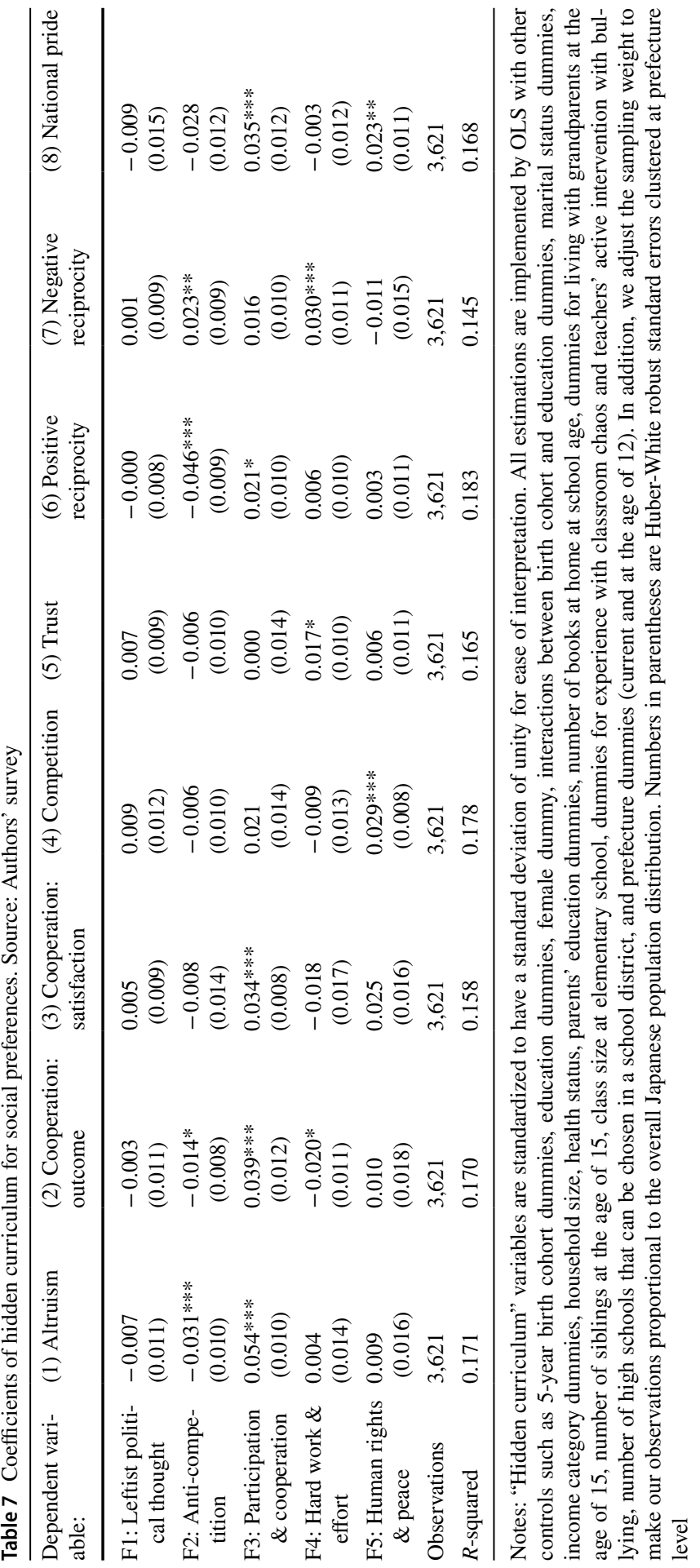


Another explanation for the negative relationship between anti-competitive education and other-regarding preferences can be provided in terms of self-esteem. In the United States, fostering self-esteem has become a major concern in school and at home based upon the belief that self-esteem leads to positive outcomes, including a rise in academic performance and better social development. However, several studies have found contradictory results: high self-esteem does not improve grades or career achievement nor does it reinforce pro-social behavior (Baumeister et al. 2003). Given that practices such as not declaring a winner in a footrace, and giving trophies for participation instead of winning, lead to pupils boosting their selfesteem, inflated belief in one's own superiority may lead to an uncooperative and nonreciprocal individual, as indeed found in the results given in Table 7.

\subsection{Economy-related preferences}

We further investigate the relationship between the hidden curriculum and economy-related preferences. Columns 1-5 of Table 8 report the results for preferences for government redistributive policy, and columns 6 to 8 report those for preferences for market institutions (see Tables 3 and 6 for the definitions of dependent variables and their summary statistics). The results in Table 8 show that the formation of economy-related preferences is also associated with the hidden curriculum. Here again, we see a contrast between "participation \& cooperation" and "anti-competition." When "participation \& cooperation" has a statistically significant positive coefficient, "anti-competition" has a negative coefficient, and when "anti-competition" has a significant negative coefficient, "participation \& cooperation" has a positive coefficient.

The results indicate that those who experienced participatory/cooperative learning ("participation \& cooperation") are more likely to approve of redistributive policies: they approve of reducing income equality and endorse government policies to impose heavier taxes on big companies (columns 2 and 3). In contrast, those who experienced anti-competitive education ("anti-competition") are more likely to oppose social security (column 5), the market economy (column 7), and labor unions (column 8). While the negative coefficient of "anti-competition" for the belief in the market economy (column 7) is plausible, the negative coefficients for redistributive policies (columns 1 to 5) may be contrary to intuition because an anti-competitive view seems to be on the opposite side of inequality, which may be a result of market competition. However, in light of our results in Table 7, which indicate that anticompetitive education may nurture an asocial outlook, the results here can be interpretable. In this sense, the results in Table 8 are consistent with the results for social preferences given in Table 7.

Looking at the other factors of the hidden curriculum, the signs of statisticallysignificant coefficients are mostly as expected. People who experienced education valuing hard work and effort are more likely to oppose reducing income inequality (row 4, column 2), but advocate social protection for the poor (row 4, column 1). This may be consistent with the results in Table 7: effort-oriented education fosters higher self-responsibility, but not selfish traits. In addition, because peace 


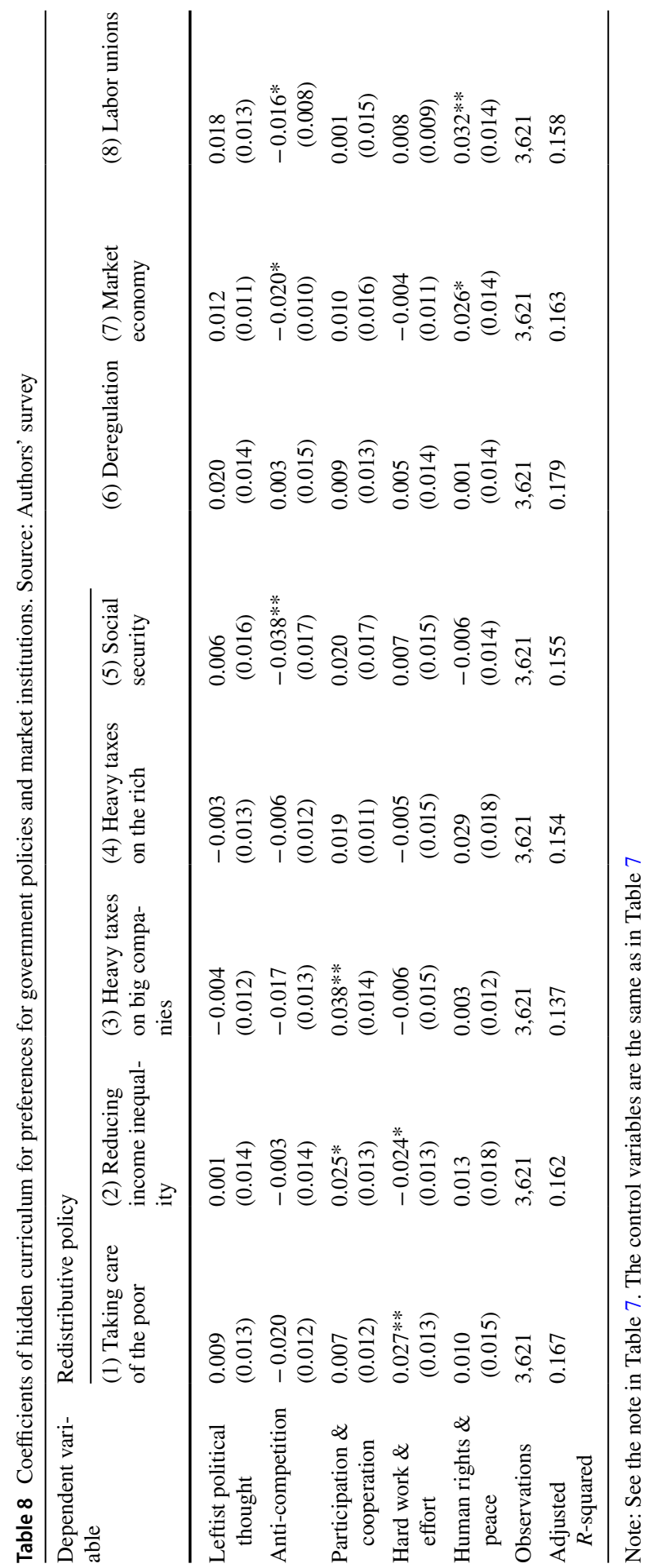


education is considered to be related to socialism in Japan, "human rights \& peace" are associated with positive appreciation for labor unions (row 5, column 8). A seemingly contradictory result is the positive relationship between "human rights \& peace" and "market economy" (row 5, column 7). People who received education emphasizing human rights and peace are expected to oppose market competition for the above reason, but awareness of human rights may be related to individualistic values.

\section{Further discussions on identification issues}

Since it is not possible to test our identification assumption directly, we examine several potential threats to the assumption indirectly and check to what extent the estimated coefficients of the hidden curriculum confound other mechanisms, if at all.

\subsection{Do parental choices result in biased estimates?}

As already discussed in Sect. 3.3, parents' school choice is a typical endogeneity issue. Here, we further test the possible influence of parents' school choice using different datasets. First, we examine the achievement gap between schools in Japan using the data from the Third International Mathematics and Science Study (TIMSS 1995). If the academic curriculum is heterogeneous across the country and/or if selfsorting into schools is common, the achievement gap should be more prominent between schools than within schools. The results in Table A2, in Online Appendix II, show that between-school disparities in test scores are considerably small in Japan compared with those in the United States and England. Surprisingly enough, in Japan, between-school disparities are smaller than within-school disparities. ${ }^{13}$ This supports the discussion in Sect. 3.3 that the national academic achievement test was not publicly disclosed before the 2000s.

Second, we explore the link between school districts and land values. If parents recognize quality schools and value those with good academic performance, land values may be affected by school district boundaries. In several developed countries, school districts affect property values (Black and Machin 2010). Thus, we investigate the effect of school zone boundaries on land prices using land value data in the Tokyo metropolitan area, where people are reputed to be more education-minded

\footnotetext{
13 In fact, this is consistent with the findings of existing studies on the achievement gap in Japan, where the gap is often attributed to differences in family backgrounds, rather than school education (Kariya and Shimizu 2004; Shimizu 2007; Matsuoka et al. 2013).
} 
(see Online Appendix III). The results show that land values are significantly different from town to town in the Tokyo metropolitan area, but the difference in school zones in a town does not influence land values. ${ }^{14}$

These results indicate that endogenous sorting into elementary schools (and thus, sorting by educational content/practices) is very unlikely in Japan. The remaining concern may be that people are more interested in the non-academic curriculum than the academic one. However, it is more difficult to observe the hidden curriculum (and its consequences) than the academic one, and therefore it is not realistic or rational that school choices are made based on the hidden curriculum. Logical reasoning also implies that such endogeneity is unlikely. If egalitarian education cultivates a cooperative attitude in people, parents with such attitudes are more likely to send their children to schools providing egalitarian education, or advocate changing the curriculum in an egalitarian direction. However, assuming that our results are driven by endogenous school choice, this would mean that parents must be aware of the specific influences of the hidden curriculum beforehand: in particular, the positive effects of participatory/cooperative education on pro-social preferences and the negative effects of anti-competitive education. However, it is not reasonable to presume that people know that participatory/cooperative and anti-competitive education, both of which are referred to as egalitarian education, have opposite influences.

Finally, we conduct a robustness check on the estimates to explore possible parental influence. If parents consider the curriculum in their child's school to be unfavorable, they may attempt to change it through the parents' association, or move to another school zone in which a preferred education is provided. We cannot directly observe these events from our dataset, but if they are more likely to happen after observing the schooling of a first-born child, we can detect this possibility by restricting the sample to first-borns. That is, the content/practices for any children born after the first child are considered to be endogenously determined. Panel A of Table 9 reports the results for the basic specification (as in Table 7) using the subsample of first-born children, a sample size of $2,005 .{ }^{15}$ Although it is expected that excluding the sub-sample of second- or later-born children attenuates the estimates in size, our estimates remain mostly unchanged or increase in their magnitude.

\footnotetext{
14 We further examine educational migration in Japan. Under the school district system, the only option available for parents when choosing a school is changing their residence. Unfortunately, no survey data focusing only on relocation for elementary education are available; however, the Employment Structure Survey, which asks the respondents about their most recent move, includes the answer "for childrearing and education" as one of 13 alternative reasons for moving. Asai et al. (2016), using the Employment Structure Survey 2002, found that among mothers with children aged 6 and under who relocated, only $8.7 \%$ of them did so for "childrearing and education." It should be noted again that this includes moves for reasons other than elementary education. For example, reasons such as childrearing and preschool education. Furthermore, inter-prefecture migration accounts for only $0.8 \%$. If parents change their residence after considering educational content/practices, inter-prefecture migration should be observed more, given that educational content/practices vary greatly from prefecture to prefecture, as mentioned in Sect. 3.2 (and also in Online Appendix I). Therefore, it is implied that migration for elementary education, in particular for better academic curriculum, is not common in Japan.

15 For brevity, we report only coefficient estimates of "participation \& cooperation" and "anti-competition" for altruism (column 1), beliefs in cooperation (columns 2 and 3), and reciprocity (columns 4 and 5). This is because Table 7 shows striking contrasts between the two factors regarding the association with the formation of these preferences and beliefs.
} 


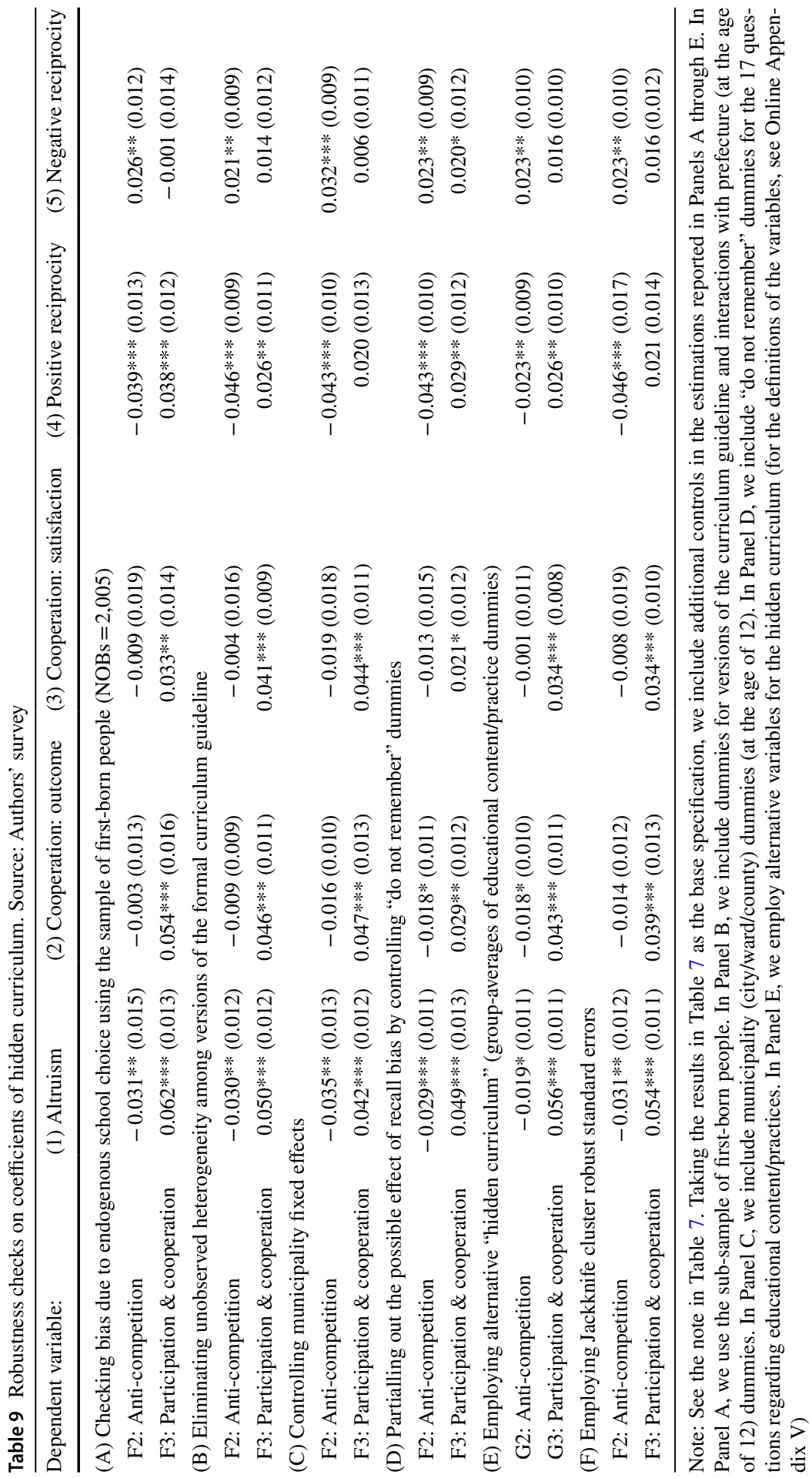




\subsection{Do other confounding factors result in biased estimates?}

We further examine the possibilities that unobserved factors other than parental choices confound the impact of the hidden curriculum on social preferences. First, we eliminate the possible influence of the revisions of the School Curriculum Guidelines. ${ }^{16}$ As discussed in Sect. 3.2, the identifying variations in the hidden curriculum stem from the generational and prefectural differences in actual educational content and practices. Although prefecture fixed effects are controlled in Table 7, there still exists the possibility that our results are driven by unobserved generational differences within prefectures. A candidate for the source of such heterogeneity might be the appearance of differing versions of the guidelines over time, and therefore we additionally control dummies for the guideline versions and their interactions with prefecture dummies (at the age of 12). Estimation results are presented in Panel B of Table 9, showing that coefficient estimates remain virtually unchanged in magnitude. Thus, unobserved heterogeneity within prefectures due to the revision of the guidelines is unlikely to influence our estimates.

Second, we address the possible influence of unobserved heterogeneity within prefectures by controlling dummies for administrative units smaller than prefectures. Because geographical or cultural factors within prefecture, or community characteristics, may confound our estimates of the hidden curriculum's influence, we check the possible influences indirectly by controlling city/ward/county (shi/ku/gun) fixed effects. The estimation results in Panel $\mathrm{C}$ show that, after controlling city/ward/ county dummies, coefficient estimates are either almost unchanged or increase in magnitude, and contrasts still exist between "anti-competition" and "participation \& cooperation." Therefore, unobserved heterogeneity within prefectures is less likely to influence our results.

Finally, we feel it necessary to mention the possibility of omitted variable bias due to unobserved teacher characteristics. One might doubt that unobserved teacher characteristics affect the selection of educational content/practices and that our estimates capture the influence of such teachers' personal qualities rather than the hidden curriculum. Fundamentally, we do not rule out the possibility of such influences through teachers because the hidden curriculum is considered to be partly based on the preferences, beliefs, and norms of teachers.

At the same time, however, we believe that, in our context, it is unlikely that our estimates confound the influence of unobserved teacher characteristics for the following reasons. First, pupils do not have the same teacher for the entirety of their primary education and therefore, the effect of a particularly influential teacher would be "smoothed out" by teachers with different levels of influence in other years. In addition, an influential teacher would not have the same level of influence on all pupils in a class or year (i.e., what some people find engaging, others might not). Moreover, our educational content/practices used in the analysis (as listed in Table 1) cannot be determined at the class (teacher) level but at the school level.

${ }^{16}$ Since the end of the Second World War, the Ministry has revised the guidelines nine times (in 1947, 1951, 1956, 1961, 1971, 1980, 1992, 2002, and 2011). 
Furthermore, given that, as a general rule, teachers cannot choose the schools in which they work, educational content/practices at schools are expected to be independent of teachers' personal characteristics. In fact, Table A1 in Online Appendix I suggests that our proxies for the hidden curriculum vary widely by prefecture: within-prefecture variations are much smaller than between-prefecture variations. This is mainly due to the educational administration system in Japan, implying that actual educational content/practices are determined at some community level.

Our estimations in Tables 7 and 8 include several controls that capture the quality of a teacher or a school (school district), such as class size, dummies for experience with classroom chaos, teachers' active intervention with bullying, and the number of high schools that can be chosen in a school district. In addition, current individual income level, which might partially capture the quality of education, is also controlled. Therefore, our estimates are unlikely to suffer from unobserved teacher characteristics.

\subsection{Does the way the hidden curriculum is measured matter?}

Another potential threat to the parameter identification is that the hidden curriculum used in this study is based on respondents' retrospective and subjective answers on past educational content/practices. A typical issue regarding retrospective data is recall bias. For instance, more intense experiences might remain in respondents' memory. Moreover, when people hold two conflicting cognitions, they might distort one to mitigate the dissonance of the other (issue of cognitive dissonance). In other words, there is a possibility that current preferences distort reports of past experiences.

In fact, as we saw in Table 2, a non-negligible number of respondents answered "do not remember." If such forgetfulness occurs in a non-random manner due to recall bias, it is possible that our proxies for the hidden curriculum are correlated with unobserved individual preferences or beliefs. However, this may not be a serious problem. The content/practices with high rates of "do not remember" answers are those with large regional differences. For example, "school assembly on atomic bomb day" is practiced mainly in western Japan. This is because Hiroshima and Nagasaki are in western Japan, and the school assembly is held during summer vacation to ensure the terrible lessons of the war are not forgotten. Therefore, memories of the school assembly are strongly connected with the date for those who experienced it. Likewise, "emergency drill on September 1" is associated with the Great Kanto Earthquake, which struck on September 1, 1923, and is, therefore, predominantly practiced in eastern Japan including the Kanto region. Thus, answering "do not remember" to a content/practice reflects the fact that the respondent received education that placed less emphasis on such content/practice. Due to this, one would expect many respondents to answer "do not remember" where they otherwise might have answered "no." As such it seems a justified approach would be to treat the answers "do not remember" and "no" as the same.

To check the influence of recall bias empirically, we also estimate several specifications, additionally controlling for the percentage of "do not remember" answers 
to the 17 educational content/practices or 17 dummy variables that take unity if the answer is "do not remember," and zero otherwise. Panel D reports the coefficient estimates of the hidden curriculum variables employing the dummy variables' specification. Although the statistical significance of some estimates decreases, the magnitude is almost unchanged. Thus, controlling for these variables does not affect our main findings. In addition, we conduct further checks for the possibility of recall bias. Table A3 in Online Appendix IV reports the estimation results where the dependent variables are "do not remember" dummies and the explanatory variables are eight social preferences and other controls. If answering "do not remember" is attributable to recall bias, we may observe that people with some kind of social preference are more or less likely to answer "do not remember" to a specific educational content/practice. The estimation results, however, mostly show no evidence of the linkage between current preferences and "do not remember" answers. Even for the exceptions that show statistically-significant relationships, no convincing evidence exists pointing to recall bias as an explanation of our findings in Table 7. Thus, it is unlikely that people intentionally forgot the educational content/practices they received or that people strongly affected by an educational content/practice are more likely to remember that content/practice.

Finally, we check the sensitivity of our results to the measurement of the hidden curriculum. Panel E shows the results using group-averages of dummy variables on the 17 educational content/practices. We divide the 17 educational content/practice dummies into several groups according to their correlation coefficients and calculate the average by group (see Online Appendix V). Because the standard deviation of factor scores used in Table 7 is unity, the group-averages are also standardized so that their standard deviation becomes unity for ease of comparison. As can be seen from the results in Panel E, the magnitude of coefficient estimates is remarkably stable. In addition, employing polychoric factor analysis with the principle factor (PF) method, instead of the PCF method used in Table 7, does not affect the results (see Online Appendix V). Therefore, our findings are not sensitive to the measurement of "hidden curriculum" variables.

\subsection{Other issues}

Finally, we examine two issues associated with the outcome and treatment variables used in the analysis. The first issue is about the specification of the dependent variables. As mentioned in Sect. 3.2, we converted respondents' five-scale answers regarding social preferences into binary responses and estimated the linear probability model of Eq. (1). To check the robustness of our results and the sensitivity to this choice, we implemented the probit model with the binary responses and the ordered probit model with the original five-scale responses. Estimation results, which are reported in Table A7 in Online Appendix VI, show that the OLS estimates in Table 7 are considerably similar to the probit and ordered probit estimates. In the case of the probit estimation, rather, the coefficient estimates are slightly larger in their magnitudes than the OLS estimates in most cases. Thus, our main findings are not sensitive to the choice of the dependent variables and method. 
The second issue is a so-called generated regressor problem. The proxies for the hidden curriculum we employ are generated from the factor analysis. Hence, potential differences between the proxies and the actual hidden curriculum may render our estimation invalid. When the measurement errors are correlated with the proxies, an OLS regression causes bias in our estimates. In this case, however, if the classical measurement error assumptions hold, the attenuation bias exists and our estimates can be considered as the lower bound of the impacts. On the other hand, when the proxies for the hidden curriculum are independent of the errors, there is no problem in estimating the impacts, but caution is needed in estimating the standard errors, since the measurement errors are included in the unobserved components of the outcome, $\varepsilon_{i}$ in Eq. (1). Therefore, we check this issue by applying the Jackknife method. ${ }^{17}$ The Jackknife cluster robust standard errors are reported in Panel $\mathrm{F}$ of Table 9. The panel shows that the standard error increases slightly and the statistical significance decreases in some cases, but the changes are not so large as to compromise our main findings.

\section{Conclusion}

This paper examined the role of elementary school education in the formation of social preferences. In the analysis, we extracted proxy factors comprising the socalled "hidden curriculum" and investigated its association with the formation of social preferences. Our main findings are summarized as follows.

First, educational content/practices at public elementary school differ greatly by region and by school despite a national educational policy and curriculum. Although it is widely believed that public elementary schools in Japan provide undifferentiated education, schools in different areas and even within the same area, in fact, do employ different educational content/practices. Second, the hidden curriculum exerts a significant influence on pupils' subsequent social preferences. In particular, education valuing student participation and cooperation is associated with positive social preferences: those who experienced participatory/cooperative learning practices are more likely to be altruistic, cooperative with others, reciprocal, and proud of their nationality. On the other hand, educational practices emphasizing anti-competition are associated with negative social preferences: those educated with anticompetitive practices are more likely to be non-altruistic, uncooperative with others, vengeful, and unpatriotic. While we do not argue strongly for the internal validity of our estimates, various checks imply that the endogeneity issues are less problematic.

On the whole, our results indicate that elementary school education plays an important role in preference formation. Thus, in line with Algan et al. (2013),

\footnotetext{
17 Another approach is to employ the bootstrap standard errors, which are usually more efficient than the Jackknife standard errors. In this study, we take the Jackknife approach because the bootstrap method is too time-consuming in the current context since we have to estimate the factor analysis in each step. In addition, differences between the bootstrap and Jackknife standard errors are negligible when the sample size is large.
} 
Cantoni et al. (2017), and Alan and Ertac (2017), this study provides evidence of horizontal/oblique socialization mechanisms through elementary education. Furthermore, our results indicate a prolonged influence of elementary schooling on subsequent preference formation, implying that education shapes the future of society through such preference formation, not just through human capital formation.

Acknowledgements This study was supported by the Japan Society for the Promotion of Science (JSPS) (grant numbers: 26245041, 15K17069 and 19K21696) and the Joint Usage/Research Center at ISER/ Osaka University. We thank Daniel Hamermesh, Hirokazu Ishise, Takehiko Kariya, Takao Kato, Daiji Kawaguchi, Katsuo Kogure, Hisaki Kono, Ilyana Kuziemko, Hodaka Morita, Wataru Nakazawa, Masao Ogaki, Yasuyuki Sawada, Kotaro Tsuru, anonymous referees of journals, and numerous participants at various seminars at the Research Institute of Economy, Trade and Industry (RIETI), Kobe University, the 7th Trans-Pacific Labor Seminar (TPLS), and Konan University for helpful comments.

Open Access This article is licensed under a Creative Commons Attribution 4.0 International License, which permits use, sharing, adaptation, distribution and reproduction in any medium or format, as long as you give appropriate credit to the original author(s) and the source, provide a link to the Creative Commons licence, and indicate if changes were made. The images or other third party material in this article are included in the article's Creative Commons licence, unless indicated otherwise in a credit line to the material. If material is not included in the article's Creative Commons licence and your intended use is not permitted by statutory regulation or exceeds the permitted use, you will need to obtain permission directly from the copyright holder. To view a copy of this licence, visit http://creativecommons.org/ licenses/by/4.0/.

\section{References}

Alan, S., \& Ertac, E. (2017). "Belief in Hard Work and Altruism: Evidence from a Randomized Experiment." HCEO Working Paper Series 2017-053. Human Capital and Economic Opportunity Working Group, University of Chicago.

Algan, Y., Cahuc, P., \& Shleifer, A. (2013). Teaching Practices and Social Capital. American Economic Journal: Applied Economics, 5(3), 189-210.

Asai, Y., Kambayashi, R., \& Yamaguchi, S. (2016). Crowding-out effect of publicly provided childcare: Why maternal employment did not increase?. Mimeo: University of Tokyo.

Baumeister, R. F., Campbell, J. D., Krueger, J. I., \& Vohs, Kathleen D. (2003). Does high self-esteem cause better performance, interpersonal success, happiness, or healthier lifestyle? Psychological Science in the Public Interest, 4(1), 1-44.

Bisin, A., \& Verdier, T. (2011). The economics of cultural transmission and socialization. In Jess Benhabib, Alberto Bisin, \& Matthew O. Jackson (Eds.), Handbook of social economics (Vol. 1A). Amsterdam: North-Holland.

Black, S. E., \& Machin, S. (2010). Housing valuations of school performance. In E. A. Hanushek, S. J. Machin, \& L. Woessmann (Eds.), Handbook of the economics of education (Vol. 3). Amsterdam: North Holland.

Cantoni, D., Chen, Y., Yang, D. Y., Yuchtman, N., \& Jane Zhang, Y. (2017). Curriculum and ideology. Journal of Political Economy, 125(2), 338-392.

Cappelen, A., John, L., Anya, S., \& Bertil T. (2017). "The Effect of Early Education on Social Preferences," HCEO Working Paper Series 2017-002.

Clots-Figueras, Irma, \& Masella, Paolo. (2013). Education, language and identity. Economic Journal, 123(570), F332-F357.

Dohmen, T., Falk, A., Huffman, D., \& Sunde, U. (2009). Homo reciprocans: Survey evidence on behavioural outcomes. Economic Journal, 119(536), 592-612.

Friedman, W., Kremer, M., Miguel, E., \& Thornton, R. (2016). Education as Liberation? Economica, 83(329), 1-30. 
Giroux, H., \& Purpel, D. (Eds.). (1983). The hidden curriculum and moral education. Berkeley, California: McCutchan Publishing Corporation.

Heckman, J. J., \& Krueger, A. (2003). Inequality in America: What role for human capital policies?. Cambridge, MA: The MIT Press.

Heckman, J. J., \& Raut, L. K. (2016). Intergenerational long-term effects of preschoolstructural estimates from a discrete dynamic programming model. Journal of Econometrics, 191(1), 164-175.

Helliwell, J. F., \& Putnam, R. D. (2007). Education and social capital. Eastern Economics Journal, 33(1), $1-19$.

Hryshko, D., Luengo-Prado, M. J., \& Sørensen, B. E. (2011). Childhood determinants of risk aversion: the long shadow of compulsory education. Quantitative Economics, 2(1), 37-72.

Kariya, Takehiko. (1995). The rise of mass education society. Tokyo: Chuokoron-Shinsha. (in Japanese).

Kariya, Takehiko, \& Shimizu, Kokichi (Eds.). (2004). The sociology of scholastic achievement. Tokyo: Iwanami Shoten. (in Japanese).

Kelly, A. V. (2009). The curriculum: Theory and practice (6th ed.). London: Sage Publications.

Kubota, K., Takahiro, I., \& Fumio, O. (2019). "Long-Term Consequences of Group Work in Japanese Public Elementary Schools." Japan and the World Economy, 52.

Matsuoka, R., Makiko, N., Tomohiko, I. (2013). "Widening Educational Disparities Outside of School: A Longitudinal Study of Parental Involvement and Early Elementary Schoolchildren's Learning Time in Japan.” RIETI Discussion Paper Series 13-E-101.

Milligan, K., Moretti, E., \& Oreopoulos, P. (2004). Does education improve citizenship? Evidence from the United States and the United Kingdom. Journal of Public Economics, 88(9-10), 1667-1695.

Shimizu, K. (2007). Schools that Overcome the Disparities of Academic Achievements among Children: Searching for Japanese Effective Schools (translated by Walter Dawson). Educational Studies in Japan: International Yearbook, 2, 107-124.

Yoshida, A., Kogure, K., \& Ushijima, K. (2009). "School choice and student sorting: Evidence from Adachi Ward in Japan. Japanese Economic Review, 60(4), 446-472.

Publisher's Note Springer Nature remains neutral with regard to jurisdictional claims in published maps and institutional affiliations. 